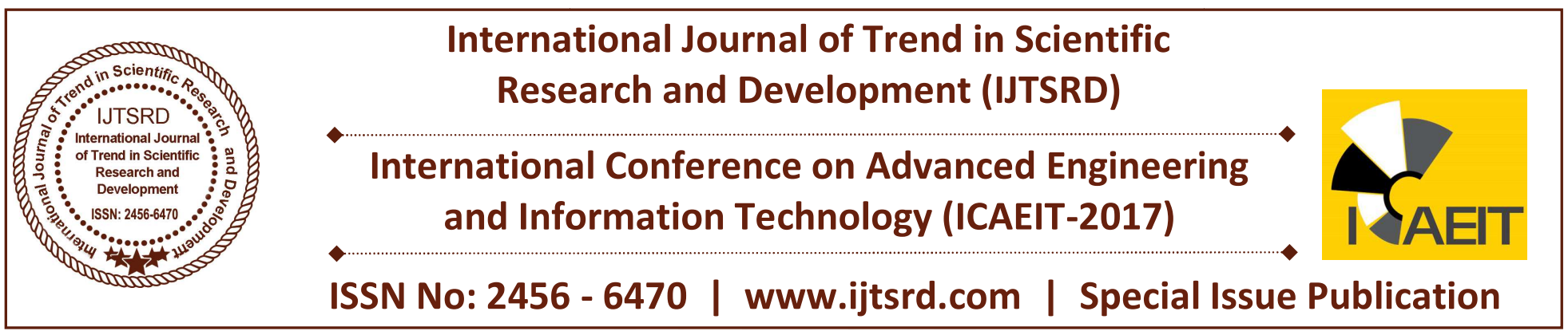

\title{
Engineering Advantages of Vegetation on Slope Stabilization
}

\author{
Farshchi Iman \\ Linton University College, Mantin, Negeri Sembilan, Malaysia
}

\begin{abstract}
There are various conventional methods used to improve stability of slope and surface erosion. They all have merits and demerits, but the use of vegetation has many advantages such as root does not corrode, they are self-repairing, regenerating and environmental friendly. This discipline has gained a global recognition for a long time and has been addressed as a new entity, "Ecological Engineering" which is defined as the design of sustainable ecosystem that integrates human society with its natural environment for the benefit of both. This paper considers the potential engineering influences of vegetation and how it can be characterized on site within a geotechnical framework for stability assessment. To gain more understanding on its soilroot interaction and effects on slope stabilization, the mechanical and hydrological effect of vegetation would be combined and their overall effect on slope stabilization and slope stability analyses would be evaluated. The results obtained for the Vetiver Grass and Lime Tree will be considered. In overall the results show the considerable improvement in the slope stability by applying vegetation on finite slope depending to their location on slope. The results also indicate that Vetiver Grass can cause significant improvement in the slope stability compare to the Lime Tree even when it is located at the crest of slope due to its roots geometry and lower weight.
\end{abstract}

Keywords: Soil, Vetiver Grass, Lime Tree, slope stability.

\section{INTRODUCTION}

The influence of vegetation can be divided into hydrological and mechanical factors, which can be beneficial or adverse to slope stability [1]. The hydrological and mechanical parameters reflecting the effect of vegetation in stability analysis are: an additional effective cohesion; an increase in weight of slice due to the vegetation; a tensile reinforcement force by the roots present on the base of each slice; wind force; possible changes in undrained soil strength due to moisture removal by the vegetation; and changes in pore water pressure. These parameters have been further explained and discussed within a geotechnical framework. Root reinforcement is a determining factor when evaluating the influence of vegetation on slope stability. There are five main functions that the plant may perform within the soil bioengineering system in vegetative structure: support, anchor, drain reinforces and armour, depending upon the type of plants used in the soil bioengineering, the nature of slope and soil characteristics. The importance of vegetation in slope stabilization and surface erosion control is enormous.

\subsection{Slopes}

Slopes may be man-made as in: cuts and fills for highways and rail-roads, earth dams, dykes for containment of water, landscaping operation for industrial and other developments, banks of canals and other water conduits and temporary excavation.

Slopes may also be naturally formed as hillsides or stream banks. At all locations where the ground is not level, there are forces which tend to cause movements of the soil from higher points to lower points. The significant importance of such forces is the component of gravity, which acts in the direction of the probable motion. Also important, but also not well recognized, is the force of seeping water. These several forces produce shear stresses throughout the soil mass and a movement will occur unless the 
shearing resistance on every positive failure surface throughout the mass is sufficiently larger than the shearing stress.

\subsection{Cause and mechanism of slope failure}

The causes of major failure of slopes are the insufficient control of surface water and the presence of local weaknesses, discontinuity, sheet jointing. Adoption of deficient geological or hydrogeological modes of slope design is the most important factor of major failures in engineered slopes. Another problem associated with the large slides is adverse groundwater conditions undetected during design and construction stage [2].

Minor slope failures are caused by surface water, the mechanism mainly involves concentrated surface runoff leading to erosion and water ingress during intense rain, inadequate maintenance generally takes the form of blocked or cracked drainage channel, and inadequate attention to proper detailing. Another cause of minor failure in slope is local weakness in the ground mass, most in soil cuts and rock cuts are associated with the presence of local weakness of weak geological material and adverse ground water build up of local transient perched water table.

Common failure mechanism of a fill slopes are flow slides due to inadequate compaction, washout and sliding and those for soil cut slopes are washout and sliding [3].

The second mechanism of failure is liquefaction which is the sudden collapse of metastable soil structure within a loose soil mass in a slope when it is subjected to a high degree of saturation under sustained shear stresses, resulting in a significant reduction of soil shear strength and leading to a flow slide type of failure which is a special case of sliding failure.

The third mechanism is washout which is detachment of part of the soil mass induced by the scouring action of running surface water.

\subsection{Mechanical effect of vegetation}

\subsubsection{Root reinforcement}

Roots embedded in soil form a composite material consisting of fibres of relatively high tensile strength and adhesion within a matrix of lower tensile strength. Researches show that vegetation could contribute the shear strength to the slope via root reinforcement and identified a series of empirical and physical based relationship between root development and soil strength. Even low root density can provide substantial increase in shear strength and the magnitude additional apparent cohesion varies with the distribution of the roots within the soil and with the tensile strength of the individual roots. [4,5].

Root reinforcement is a function of root strength, interface friction between root and soil and the distribution of root within the soil and root-reinforced soil is more able to resist continued deformation without loss of residual strength than soil alone [5]. The magnitude of the mechanical reinforcing effect of vegetation is a function of the following root Properties: density, tensile strength, tensile modulus, length/diameter ratio, surface roughness, alignment; straightness and angularity and orientation to the direction of principal strains [1].

\subsubsection{Root area ration}

The ability of a tree to reinforce soil will depend, not only in the depth to which its root systems extend but also on the total cross-sectional area of its roots at the given depth [6, 7, 8 and 9].

\subsubsection{Root tensile strength}

Nilaweera and Nutalaya [10] pointed out that the pullout resistance of a tree is generally controlled by its root strength and morphological characteristics and the pull-out resistance of the tree increased with root length distribution and the depth of root penetration.

\subsubsection{Anchorage, arching and buttressing}

The taproot and the sinker roots of many tree species penetrate into the deeper soil layers and anchor them against down-slope movement.

\subsubsection{Surcharging}

Surcharge is the effect of the additional weight on a slope resulting from the presence of vegetation. Surcharge could have adverse effects, although it can be beneficial depending on the slope geometry, the distribution of vegetation cover and the properties of the soil.

\subsubsection{Wind loading}

Wind loading is usually only significant when the wind speed is stronger than $11 \mathrm{~m} / \mathrm{s}$. The forces induced in vegetation by wind can sufficient to disturbed upper soil layer thus, initiate landslips [1]. 
Wind loading is particular relevant when considering the stability of individual trees, but is of lesser significant for general slope stability, where the wind forces involved represent a much smaller proportion of the potential disturbing forces, and trees within a cluster (stand) are sheltered to some extend by those at the edge.

\subsection{Hydrological effect of vegetation}

\subsubsection{Rainfall interception}

Vegetation intercepts a proportion of the incoming rainfall, part of which is stored on the leaves and stems of the plants and is returned to the atmosphere by evaporation. Thus, interception decreases the rate and volume of rainfall reaching the ground surface.

\subsubsection{Surface water runoff}

The combination of surface roughness, infiltration and interception, surface water runoff from the vegetated areas is much less than that of bare soil.

\subsubsection{Infiltration}

Vegetation increases the permeability and infiltration of the upper soil layers due to roots, pipes or holes where the roots have decayed, increased surface roughness.

\subsubsection{Evaporation and transpiration}

Hydrological effects involves the removal of soil water by evaporation through vegetation, which lead to an increase in soil suction or reduction in pore water pressure, hence an increase in the shear strength [11]. Therefore, vegetation affects slope stability hydrologically by extracting soil moisture through transpiration. Apart from increasing the strength of soil by reducing its moisture content, evaporation by plant reduces the weight of the soil mass.

\section{Materials and methods}

The study has been carried out within the United Kingdom and its environs as this study is the continuous of Rees and Ali [11 and 12] works with temperate climate with plentiful rainfall all year round. The plant used for the research will be limited to the mature lime tree (Tilia) and Vetiver Grass. The transpiration rate, weight; root geometry of these plants shall be used. Mechanical properties of Boulder clay soil would be considered. Analyzing the factor of safety of vegetation on finite slopes will be done by using SLIP4EX computer program.
The equations used in the SLIP4EX spreadsheet are derived from the basic limit equilibrium stability equation [13]:

By resolving forces to determine $\mathrm{N}^{\prime}$, the full stability equation based on effective forces will be obtained [14].

The simple mathematical form of the Greenwood stability equations with the Factor of Safety simply expressed by a summation of restoring and disturbing moments or forces makes the inclusion of additional forces due to ground reinforcement, anchors or vegetation effects relatively straightforward.

It is not straightforward to add these additional forces in the Bishop and other ,sophisticated published solutions where the global factor of safety is applied to the shear strength parameters for each slice of the analysis resulting in some unrealistic force scenarios for the slices where anchor and reinforcement loads are applied [15]. The General equation 2 is adapted for inclusion of the vegetation effects, reinforcement and hydrological changes, Figure 2, as follows [16, 17 and 18]:

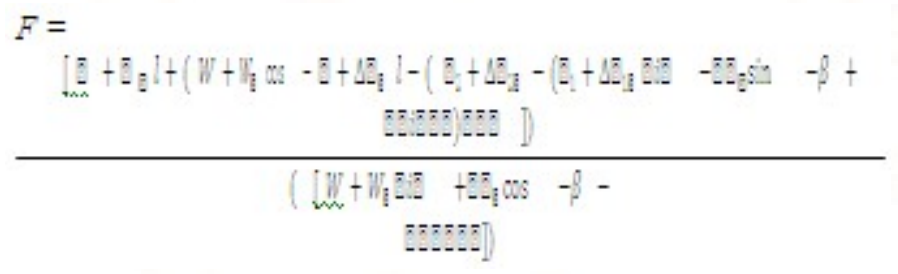

But in the SLIP4EX changes in ground water table due to vegetation are included however the changes in ground water table employed in their work were taken directly from piezometer readings no numerical simulation of this process was involved. The study was based on the effective stress approach and as such is valid only for saturated soils. In this study, the stability of an unsaturated soil slope is considered in relation to soil suction created by the plant water-uptake process. These changes primarily affect the matric suction component only. Hence matric suction is considered in this study by adding equation [4] into the SLIP4EX [19].

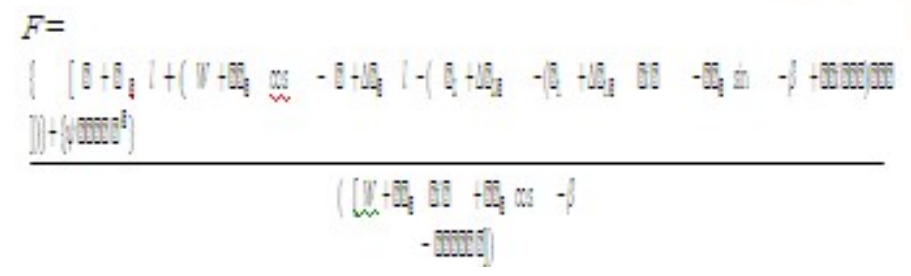




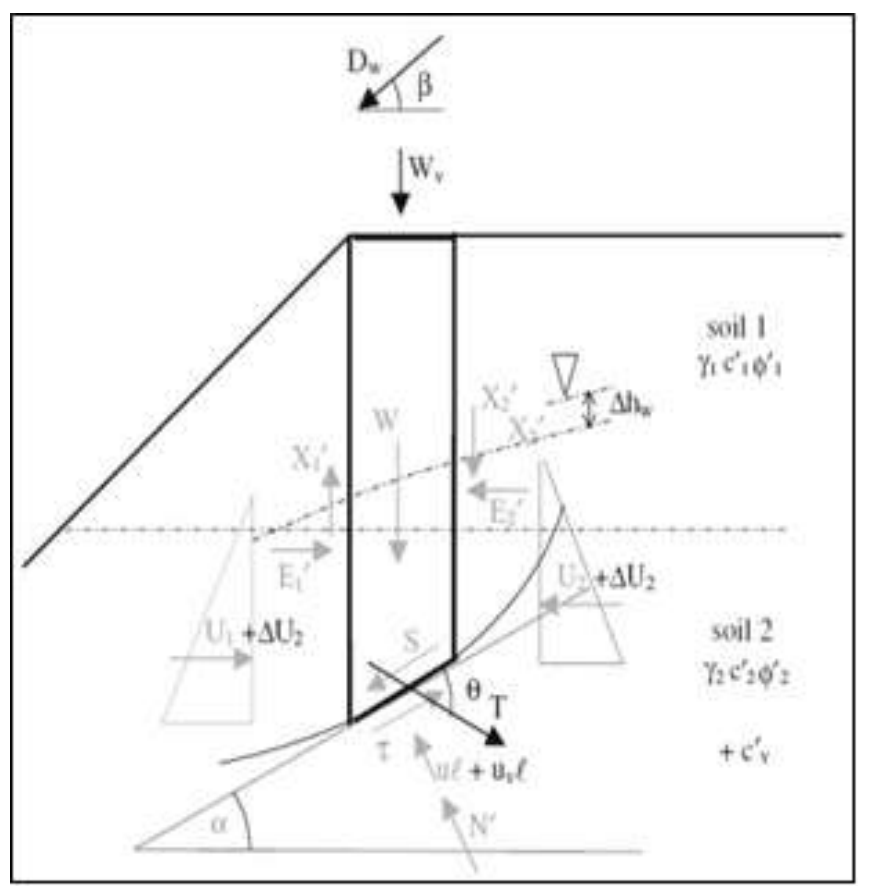

Figure1. Additional forces due to vegetation, reinforcement and hydrological changes [19]

\section{Results and discussion}

The analyzed Factor of Safety (FOS) will be discussed by applying the vegetation at three different positions on the slope as shown in Figure 2.

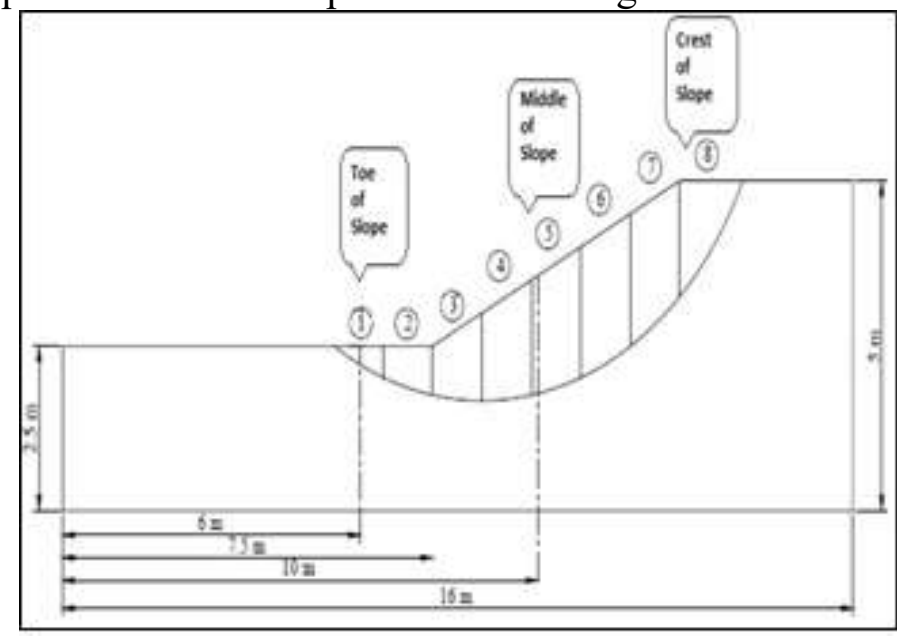

Figure2 . Slope profile showing the position of the vegetation on the slope

Referring to Table 1 , the use of lime tree at the toe of the slope has shown an increase of $8.75 \%$ in the Factor of Safety (FOS) and an increase of 3.75\% at the middle of slope. However, is has a reverse effect when the lime tree was used at the crest of slope with the difference of $2.75 \%$. On the other hand, the use of Vetiver Grass at the toe, middle and at the crest of slope has indicated increased percentages of FOS especially at the middle of the slope, by showing an increase of $3 \%$.
Table1. Comparisons of the different Factor of Safety (FOS) and the percentage difference without the effect of vegetation, with the effect of Mature Lime Tree and with the effect of the Vetiver Grass

\begin{tabular}{lcccccc} 
Position & $\begin{array}{l}\text { FOS Without } \\
\text { Effect of the } \\
\text { Vegetation }\end{array}$ & $\begin{array}{l}\text { FOS with the } \\
\text { Lffect of the } \\
\text { Mature Lime } \\
\text { Tree }\end{array}$ & $\begin{array}{c}\text { Percentage } \\
\text { of difference }\end{array}$ & $\begin{array}{l}\text { FOS with the } \\
\text { Effect of the } \\
\text { Vetiver Grass }\end{array}$ & $\begin{array}{l}\text { Percentage of } \\
\text { difference }\end{array}$ \\
\hline Toe of slope & 1.6 & 1.74 & +8.75 & 1.64 & +2.4 \\
\hline Middlc of slope & 1.6 & 1.66 & +3.75 & 1.65 & +3.00 \\
\hline Crest of slope & 1.6 & 1.54 & -2.5 & 1.64 & +2.4
\end{tabular}

\section{CONCLUSION}

From the results obtained, it can be concluded that the parameters discussed play important roles in the slope stability. Upon completing this research, the overall conclusion indicates the positive effect of vegetation on the analyzed Factor of Safety (FOS). These results have shown even more that $8.75 \%$ increase in the FOS when the lime tree was located at the toe of slope. On the other hand by using the Vetiver Grass, the FOS at the toe of slope has shown only $2.4 \%$ increase compare to the situation without any effect of vegetation. This can be due to the effect of the weight of lime tree which is much heavier than the weight of the Vetiver Grass on the slope which can be positive in this situation. It has been observed that the effect of the weight of tree can be reversed when the lime tree located at the crest of the slope and shows the reduction in FOS. On the other hand at the middle of slope both the Vetiver Grass and Lime tree have an equal positive effect on slope stabilization and the FOS has increased approximately $3 \%$ in compare to the situation of without any vegetation.

\section{References}

1. Coppin N. J. and Richards I. J., Use of Vegetation in Civil Engineering. Butterworths, London., 1990.

2. Wong, H. N., "Recent advances in slope engineering in Hong Kong", $14^{\text {th }}$ Southeast Asian Geotechnical Conference, Hong Kong, Vol. 1, 641-659., 2001.

3. Wong, H. N., Ho, K. K. S. and Chan, Y. C., "Assessment of consequence of landslides", Proc. of International Workshop on Landside Risk Assessment, Honolulu, Hawaii, USA, 111-149., 1997. 
4. Wu T. H., McKinell W. P. and Swanston D. N. Strength of Tree Roots and Landslides on Prince of Wales Island, Alaska, Can. Geotech. J. 16 (1) 19-33., 1979.

5. Abernethy B and Rutherford I. D., The distribution and strength of riparian tree roots in relation to riverbank reinforcement, Hydrological processes, 15: 63-79., 2001.

6. Martin R. P., Landscaping and Bioengineering in Hongkong, Proceeding of the 14th Southeast Asian Geotechnical Conf., Hongkong, Dec., 2001, pp 661-670., 2001.

7. Barker D. H., Innovative Bioengineering Techniques for Rapid slope stabilization, proceeding of the 14th Southeast Asian Geotechnical Conference, Hongkong, pp 697702., 2001.

8. Martin R. P., Li C. O. and Pryor M. R. Bioengineering and Landscape Treatment of slopes and Retaining Wall in Hongkong"s Landslip Preventive Measure Programme, Pro. of the 14th Southeast Asian Geotech. Conf., Hongkong, pp 863-868., 2001.

9. Dorker B. B. and Hubble T. C. T., Earth Reinforcement potential for four Species as Determined by Root System Architecture, Proceeding of the 14th Southeast Asian Geotechnical Conference, Hongkong, pp 741744., 2001.

10. Nilaweera N. S and Nutalaya P. Role of Tree Roots in Slope Stabilization, Bull. Eng. Geol. Env, 57:337-342., 1999.

11. Rees S. W. and Ali N. Seasonal water uptake near tree: a numerical and experimental study,
Geomechanics and Geoengineering Vol. 1 No. 2 129-138., 2006.

12. Rees S. W. and Ali N., The influence of treeinduced suctions on slope stability., 2006.

13. Lambe T. W. and Whitman R. V. Soil Mechanics, Wily, New York, pp. 364-365., 1969.

14. Greenwood J. R. Effective stress stability analysis, Discussion in Proceedings of the 9th European Conference on Soil Mechanics and foundations, Dublin, 1987, 3, pp.1082- 1083., 1987.

15. Krahn J. R. M. Hardy Keynote Address, The limits of limits equilibrium analysis, Canadian Geotechnical Conference Calgary, September, 2001.

16. Greenwood J. R., Assessing the Contribution of vegetation to slope Stability, Proceeding of the Institution of Civil Engineers, Geotechnical Engineering 157, Issue GE4 pp 199-207., 2004

17. Greenwood J. R., Assessing the Contribution of vegetation to slope Stability, Proceeding of the Institution of Civil Engineers, Geotechnical Engineering 157, Issue GE4 pp 199-207., 2004.

18. Greenwood J. R., SLIP4EX- A program for routine Slope stability analysis to include the effects of Vegetation, reinforcement and hydrological changes, Geotechnical and Geological Engineering, Springer 24:449-465., 2006.

19. Farshchi I, Soil-Root Interaction and Effect on Slope stabilization, Master Thesis, University Technology Malaysia., 2009. 